Dr. A. Gnanamani

CHORD

Central Leather Research Institute

Adyar, Chennai

Tamil Nadu

India

Email: agmani_2000@yahoo.com

Dear Editor,

Please find enclosed with the research article entitled "ANTI-CARIOGENIC PROPERTIES OF Psidium guajava Linn. ON Streptococcus mutans” submitted for publication in your esteemed Journal "Journal of Agricultural and Food Chemistry". The article is prepared as per the instructions provided. Followed by the text and references, tables and figures are enclosed. No colour figures are enclosed.

Regarding the significance of the article, in the present study, the effect of the plant extract on clinical strains was carried our and the results are compared with the type strains. It has been understand that, the chosen plant has significant effect in reducing the cariogenic properties of both the clinical as well as type strains of Streptoccoccus mutans. The results are highly comparable. Hope, to our knowledge, this will be first kind of report for the clinical strains.

Kindly acknowledge the receipt of the mail.

With regards

Dr. A. Gnanamani 


\section{Reviewers List}

1. Dr. E. Benjavongkulchai

Department of Biochemistry

Faculty of Dentistry

Chulalongkorn University,

Henri-Dunant Road

Bangkok 10330, Thailand

Tel: +66-2-2188673

Fax: +66-2-2553058

Email: Em-on.B@chula.ac.th

2. Dr. Zubaidah Haji Abd Rahim

Department of Oral Biology

Faculty of Dentistry

University of Malaya

Kuala Lumpur, Malaysia

Tel: + 60 -3-79674851

Fax: +60-3-79674536

Email: zubaidar@um.edu.my

3. Dr. Akio Yanagida

Department of Analytical Chemistry

School of Pharmacy

Tokyo University of Pharmacy and Life Science

1432-1 Horinouchi, Hachioji

Tokyo 192- 0392, Japan.

Tel: +81-426-76-4546

Fax: +81-426-76-4542

Email: yanagida@ps.toyaku.ac.jp

4. Dr. Paula B. Andrade

REQUIMTE/Servico de Farmacognosia

Faculdade de Farmacia

Universdidade do Porto,

R. Anibal Cunha 164, 4050-047, Porto, Portugal.

Tel: + 351-222078935

Fax: +351-222003977

Email: pandrade@ff.up.pt 